\title{
Stromal-Cell-Derived Factor (SDF) 1-Alpha Overexpression Promotes Bone Regeneration by Osteogenesis and Angiogenesis in Osteonecrosis of the Femoral Head
}

\author{
Fan Yang Feng Xue Junjie Guan Zeng Zhang Jimin Yin Qinglin Kang \\ Department of Orthopedic Surgery, Shanghai Jiao Tong University Affiliated Sixth People's Hospital, \\ Shanghai, China
}

\section{Key Words}

Osteonecrosis of the femoral head • Bone marrow stem cells $\bullet$ SDF-1 $\alpha$

\begin{abstract}
Background/Aims: Osteonecrosis of the femoral head (ONFH) is a devastating orthopedic disease. Previous studies suggested that stromal-cell-derived factor (SDF)-1 was involved in osteogenesis and angiogenesis. However, whether SDF-1 potentiates the angiogenesis and osteogenesis of bone marrow-derived stromal stem cells (BMSCs) in ONFH is not clear. Methods: BMSCs were transfected with green fluorescent protein (GFP) or the fusion gene encoding GFP and SDF- $1 \alpha$, and transgenic efficacy was monitored by immunofluorescence. The expression of SDF-1 $\alpha$, runt-related transcription factor 2 (Runx2), osteocalcin (OCN), and alkaline phosphatase (ALP) at the mRNA level was measured by real-time polymerase chain reactions (RT-PCR). The expression of SDF-1 $\alpha$, Runx2, OCN, and $p-S m a d 1 / 5$ were measured at the protein level by Western blot. Transwell migration assay and tube formation assay were utilized to detect the angiogenesis in vitro, whereas the in vivo angiogenesis was monitored by angiography. Immunohistological staining and micro-CT scanning were conducted to assess the histological changes in morphology. Results: In vitro, SDF-1 $\alpha$ overexpression in BMSCs promoted osteogenic differentiation and upregulated the expression of osteogenicrelated proteins, such as ALP, Runx2, OCN, and p-Smad1/5. In the methylprednisolone induced ONFH rat model used in our investigation, the overexpression of SDF-1 $\alpha$ in BMSCs promoted significantly more bone regeneration and the expression of OCN and Runx2 as compared with the effect of vehicle overexpression. Moreover, the morphology of ONFH was ameliorated after the transplantation of BMSCs with SDF-1 $\alpha$ overexpression. Furthermore, SDF-1 $\alpha$ overexpression in BMSCs significantly increased osteoblastic angiogenesis as indicated by the increased tube formation ability, CD31 expression, and vessel volume. Conclusion: SDF$1 \alpha$ overexpression in BMSCs promotes bone generation as indicated by osteogenesis and angiogenesis, suggesting SDF-1 $\alpha$ may serve as a therapeutic drug target for ONFH treatment.
\end{abstract}




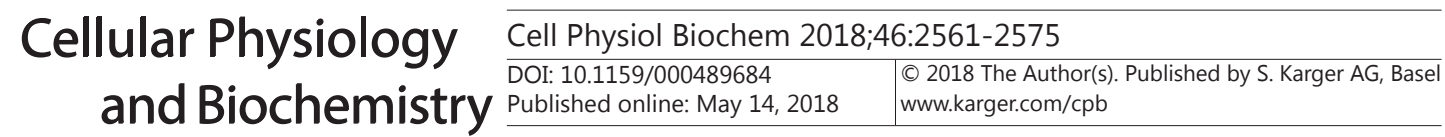

Yang et al.: SDF-1 $\alpha$ Promotes Bone Formation in ONFH

\section{Introduction}

Osteonecrosis of the femoral head (ONFH) is a devastating disease, which is characterized by cellular demise within the femoral head [1], progressive deterioration of the hip joint [2], and severely lowered quality of life [3, 4]. Although corticosteroid usage [5], alcohol consumption [6,7], and trauma [8] have been identified as risk factors for ONFH, its pathogenesis remains poorly understood. Currently, surgical prevention is the conventional therapeutic strategy, which is invasive and may decrease the quality of life. Therefore, the identification of novel nonsurgical modalities is warranted.

Bone marrow-derived stromal stem cells (BMSCs) have been widely used in tissue regeneration or repair due to their self-renewal potential and multi-differentiation capability [9-14]. Preclinical study suggested that bone healing after autologous BMSCs treatment for ONFH begins two weeks after the transplantation, and complete healing is achieved after nine weeks [15]. A five-year follow-up study revealed that the combination of implantation of autologous bone marrow cells and auto-iliac cancellous bone grafts generated comparable clinical results with those of head-preserving procedures in medium-sized lesions [16], indicating that BMSCs implantation is promising for ONFH treatment. The findings of a previous investigation demonstrated that the Akt activator and cordycepin promoted BMSC-induced osteogenesis $[17,18]$. Furthermore, P-glycoprotein (P-gp) overexpression was found to decrease the risk of steroid-induced ONFH [19] . The latter risk was alleviated by rifampicin likely through enhancing P-gp activity [20], whereas glucocorticoid-induced ONFH was successfully prevented by treatment with Vitamin K2 [21]. Moreover, augment the expression of BMP-2 and BFGF in BMSCs promoted bone repair of ONFH [22]. These results suggest that multiple factors are involved in the therapeutic effects of BMSCs on ONFH, and additional treatment with drug or transgenic modification may promote their efficacy. Nevertheless, the underlying mechanisms of these activities are not clearly elucidated.

Stromal-cell-derived factor (SDF) 1-alpha is a chemokine that is involved in immune cell activation, differentiation, and migration [23]; tumorigenesis [24]; wound healing [25]; corneal epithelium regeneration [26]; and tissue repair [27]. Of note, previous studies reported that SDF-1 $\alpha$ promoted osteoclastogenesis [28] and stem cell survival and development [29], and regulated osteogenic differentiation [30]. It is noteworthy that the conditional inactivation of SDF-1 impaired osteoblast development and differentiation [31], and antagonizing SDF-1/CXCR4 signaling altered fracture repair [32]. Furthermore, the SDF-1/CXCR4 signaling pathway is of vital importance in mesenchymal stem cell-induced osteogenic differentiation [33], and the upregulation of CXCR4 enhanced engraftment and bone mechanics in osteogenesis imperfecta [34]. Moreover, several studies suggested that SDF-1 is closely associated with angiogenesis, which is essential for osteogenesis [35]. Importantly, the downregulation of SDF-1 achieved by treatment with crude fucoidan extract lowered the vascularization in osteosarcoma [36]. In addition, melittin was established to decrease the endothelial progenitor cell-mediated angiogenesis via SDF- $1 \alpha$ inhibition in osteosarcoma [37]. Perrucci et al. reported that the SDF-1/CXCR4 axis was involved in cyclophilin A-induced neo-angiogenesis [38]. As known, osteogenesis and angiogenesis are essential for bone regeneration; therefore, it is reasonable to hypothesize that SDF-1 may play critical roles in ONFH treatment. The present study aimed to reveal the role of SDF-1 in BMSCs induced bone regeneration for ONFH treatment.

\section{Materials and Methods}

\section{Human BMSC isolation and transfection}

Bone marrow samples were obtained from patients undergoing hip arthroplasty, and BMSCs were isolated following the procedures described in previous studies [21, 39]. Cells were maintained with $\alpha$-minimum essential medium ( $\alpha$-MEM; Gibco, USA), supplemented with $10 \%$ (v/v) fetal bovine serum (FBS, Hyclone, USA) and $1 / 100$ penicillin-streptomycin in humidified atmosphere of $5 \% \mathrm{CO}_{2}$ at $37{ }^{\circ} \mathrm{C}$. Cells 


\section{Cellular Physiology Cell Physiol Biochem 2018;46:2561-2575 \begin{tabular}{l|l} 
DOI: 10.1159/000489684 & $\begin{array}{l}\text { ( ) 2018 The Author(s). Published by S. Karger AG, Basel } \\
\text { www.karger.com/cpb }\end{array}$
\end{tabular}}

Yang et al.: SDF-1 $\alpha$ Promotes Bone Formation in ONFH

were passaged when they reached $80 \%-90 \%$ confluence. Then, after three to six passages, the cells were analyzed by flow cytometry and maintained for further use. All patients provided written informed consent, and the Institutional Review Board of Shanghai Jiao Tong University Affiliated Sixth People's Hospital (Shanghai, China) approved the experimental procedures.

Third-passage BMSCs were transfected with a lentiviral plasmid carrying the green fluorescent protein (GFP) and SDF-1 $\alpha$ (GeneChem, China) or a lentiviral plasmid carrying GFP only (GeneChem). The transfected cells were named SDF- $1 \alpha$-GFP-BMSCs or GFP-BMSCs, whereas the non-transfected cells were termed as control. Seventy-two hours later, flow cytometry was utilized to select stable transgenic cells.

\section{Flow cytometry}

For phenotypic characterization, $2 \times 10^{5}$ BMSCs were incubated with fluorescein CD34 (Bioscience Pharmingen), CD 44 (eBioscience, USA), CD90 (eBioscience), CD29 (Bioscience Pharmingen), or HLA-DR (eBioscience) at a dilution rate of 1:100 for $30 \mathrm{~min}$ at $4{ }^{\circ} \mathrm{C}$. Then, flow cytometry was carried out using FACSCalibur flow cytometer (Becton Dickinson, USA). FlowJo 7.6.5 software (Tree Star Inc., Ashland, OR, USA) was used for data analysis.

Transfected BMSCs were trypsinized and suspended in phosphate buffer saline (PBS) containing 10\% FBS. Further, flow cytometry was conducted using a FACSCalibur flow cytometer (Becton Dickinson, USA) to sort GFP fluorescence-labeled cells. The sorted cells were suspended with culture medium and subjected for further use.

\section{Western blot analysis}

Proteins were extracted with RIPA lysis buffer (Beyotime, China), and protein concentration was measured by Bradford assay (BioRed, USA). Equal amounts of protein (20 $\mu \mathrm{g} / \mathrm{lane})$ were separated by sodium dodecyl sulfate-polyacrylamide gel electrophoresis (SDS-PAGE, 8\%-12\%) and transferred to a PVDF membrane (Millipore, USA). Then, the membranes were blocked with 5\% (w/v) non-fat milk for $1 \mathrm{~h}$ at room temperature and incubated with primary antibodies against Runx2 (Abcam, Cambridge, MA, USA, 1:1, 000), SDF-1 $\alpha$ (Abcam, 1:1, 000), OCN (Abcam, 1:1, 000), p-Smad1/5 (Abcam, 1:1, 000), CD31 (Abcam, 1:1, 000) and glyceraldehyde-3-phosphate dehydrogenase (GAPDH, Abcam, 1:1, 000) at $4{ }^{\circ} \mathrm{C}$ overnight. Afterwards, the membranes were incubated with secondary antibodies for $2 \mathrm{~h}$ at $37^{\circ} \mathrm{C}$. The proteins were visualized using enhanced chemiluminescence (ECL, Beyotime), and GAPDH was employed as the reference protein.

\section{Real-time polymerase chain reactions (RT-PCR)}

Total RNA was extracted by the TRIzol (Invitrogen, USA) method. RNA was reverse-transcribed to cDNA according to the manufacturer's instructions (Takara, Japan). The expression levels of SDF-1, ALP, OCN, and Runx2 at the mRNA level were measured with TransStart Tip Green qPCR SuperMix (TransGen Biotech, USA). The following cycling conditions of RT-PCR were utilized: $95{ }^{\circ} \mathrm{C}$ for $30 \mathrm{~s}$ and 40 cycles at 95 ${ }^{\circ} \mathrm{C}$ for $10 \mathrm{~s}$ and at $60^{\circ} \mathrm{C}$ for $30 \mathrm{~s}$. The expression of mRNAs was calculated by the $2^{-\Delta \Delta \mathrm{Ct}}$ method, and $\beta$-actin was used as a reference gene. The primers for RT-PCR are listed in Table 1. All experiments were performed in triplicate.

\section{Immunofluorescence staining}

Approximately $1 \times 10^{5}$ BMSCs were cultured on glass coverslips for $24 \mathrm{~h}$. Next, the cell medium was rinsed with cold PBS and fixed with $4 \%$ formaldehyde for $30 \mathrm{~min}$. Then, the coverslips were mounted, and observations were performed under a laser confocal scanning microscope (Olympus, Japan).

\section{Induction of osteogenic differentia-} tion

A total of $2 \times 10^{5}$ GFP-BMSCs, $20 \%$ SDF-1 $\alpha$-GFP-BMSCs (transfected cell/ non-transfected cell), or $100 \%$ SDF- $1 \alpha$ GFP-BMSCs were seeded in a 24-well plate. Further, osteogenic differentiation

Table 1. The primers sequences used for qRT-PCR

\begin{tabular}{lcc}
\hline Genes & Forward primer sequence $\left(5^{\prime}-3^{\prime}\right)$ & Reverse primer sequence (5'-3') \\
\hline SDF-1 $\alpha$ & ATGAACGCCAAGGTGGTGGT & TTGTTCAGGGCTTCTCCAG \\
Runx2 & CCGAGACCAACCGAGTCATTT & AAGA \\
& A & \\
OCN & TCAACAATGGACTTGGAGCCC & AGCTCGTCACAATTGGGGTT \\
ALP & CAAGGATGCTGGGAAGTCCG & CTCTGGGCGCATCTCATTGT \\
$\beta$-actin & GTCATCCATGGCGAACTGGT & CGTCATCCATGGCGAACTGG
\end{tabular}




\section{Cellular Physiology Cell Physiol Biochem 2018;46:2561-2575 \begin{tabular}{c|c|c|}
\hline DOI: 10.1159/000489684 & (c) 2018 The Author(s). Published by S. Karger AG, Basel
\end{tabular} \\ Yang et al. SDF-1 $1 \alpha$ Promotes Bone Formation in ONFH}

was induced by preconditioned induction medium containing $10^{-2} \mathrm{M} \beta$-sodium glycerophosphate, $50 \mu \mathrm{g} / \mathrm{mL}$ L-ascorbic acid, and BMSCs supernatants. The culture medium was replaced every three days.

\section{Chondrogenic differentiation induction}

A number of $2 \times 10^{5}$ BMSCs were seeded in a 24-well plate. Then cells were cultured in chondrogenic differentiation media (Cyagen Biosciences, USA) for 4 weeks according to the manufacturer's instruction. The chondrocytes were measured by Toluidine staining and observed under a light microscope (Leica, Japan).

\section{Adipogenic differentiation induction}

For adipogenic differentiation, $2 \times 10^{5}$ BMSCs were seeded in a 24 -well plate and maintained with adipogenic induction medium (Cyagen Biosciences) for 3 weeks in line with manufacturer's protocol. Then Oil red staining was used to detect adipocytes and observed under a light microscope (Leica).

\section{Cell counting kit-8}

We seeded 2x $10^{4}$ BMSCs, GFP-BMSCs and SDF-1 $\alpha$-GFP-BMSCs in 96-well microplates and cells were cultured for $72 \mathrm{~h}$. At the $24 \mathrm{~h}$ and $72 \mathrm{~h}$ time points, cell viability was measured by CCK- 8 (Beyotime, China) according to instructions. The optical density was detected at $450 \mathrm{~nm}$ with a microplate reader (Bio-Rad, USA).

For EA. Hy926 cell viability assay, approximately $2 \times 10^{4}$ EA. Hy926 cells were seeded in 96-well microplates and cells were cultured with the supernatants of BMSCs, 20\% SDF-1 $\alpha$-GFP-BMSCs and $100 \%$ SDF- $1 \alpha$-GFP-BMSCs in with or without MP for $72 \mathrm{~h}$. Then, cell viability was detected by CCK- 8 as aforementioned.

\section{Cell apoptosis}

Post transfection of GFP or SDF1- $\alpha$ in BMSCs, about $1 x 10^{5}$ BMSCs, GFP-BMSCs and SDF-1 $\alpha$-GFP-BMSCs were collected. Then cells were incubated with Annexin V-FITC/PI apoptosis detection kit (Becton Dickinson) according to instructions. Then, flow cytometry was carried out using FACSCalibur flow cytometer (Becton Dickinson). FlowJo 7.6.5 software (Tree Star Inc.) was used for data analysis.

\section{ALP staining}

Seven days after the induction of osteogenic differentiation, the expression of ALP was measured according to the manufacturer's protocols (Beyotime, China).

\section{Alizarin red staining}

Twenty-one days post-osteogenic differentiation induction, cells were fixed with $4 \%$ paraformaldehyde and stained with alizarin. Then, the cells were visualized under a light microscope (Olympus, Japan).

\section{Transwell migration assay}

Approximately $2 \times 10^{5}$ GFP-BMSCs, 20\% SDF-1 $\alpha$-GFP-BMSCs (transfected cell/ non-transfected cell), or $100 \%$ SDF-1 $\alpha$-GFP-BMSCs preconditioned with or without methylprednisolone (MP, Pfizer, USA) in serum free medium were plated in Matrigel-coated Transwell in filter chambers (in the upper chamber). A culture medium containing 10\% FBS, placed in the lower chamber, was used as a chemoattractant. The concentration of MP was $5 \times 10^{-5} \mathrm{M}$ for all in vitro studies. Twenty-four hours later, the membranes were fixed with ethanol and stained with crystal violet. Then, the membranes were mounted and observed under a light microscope (Olympus, Japan), and the migrated cells were counted in five random fields.

\section{Tube formation assay}

EA. Hy926 cell obtained from the American Type Culture Collection (Rockville, MD) was used for tube formation assay. Briefly, matrigel (BD, USA) was plated in a 12-well plate and kept at room temperature to allow it solidification. A number of $2 \times 10^{6} \mathrm{Hy} 926$ cells were collected, re-suspended with cell supernatants of $20 \%$ SDF-1 $\alpha$-GFP-BMSCs (transgenic cell/normal cell), $100 \%$ SDF- $1 \alpha$-GFP-BMSCs, or GFP-BMSCs, and seeded to matrigel-coated plates. Twenty-four hours later, tube formation was observed with a light microscope (Olympus, Japan). 


\section{Cellular Physiology Cell Physiol Biochem 2018;46:2561-2575 \begin{tabular}{ll|l}
${ } }$ & $\begin{array}{l}\text { ○ } 2018 \text { The Author(s). Published by S. Karger AG, Basel } \\
\text { www.karger.com/cpb }\end{array}$ \\
\hline
\end{tabular}}

Yang et al.: SDF-1 $\alpha$ Promotes Bone Formation in ONFH

Animal model and grouping

Specific pathogen-free Sprague-Dawley (SD) rats, weighing $260 \pm 20$ g, were obtained from the Chinese Science Academy and divided into five groups: control, MP, MP, MP + GFP-BMSCs, and MP+SDF- $1 \alpha-G F P-$ BMSCs. Next, the rats were intramuscularly injected with MP $(20 \mathrm{mg} / \mathrm{kg} / \mathrm{d})$ for three continuous days per week for three weeks. A number of $1 \times 10^{7}$ GFP-BMSCs or SDF- $1 \alpha$-GFP-BMSCs were injected into the tibia of the rats in the experimental groups, whereas the rats in the control group received no treatment. The use of animals was approved by the Animal Research Committee at Shanghai Jiao Tong University Affiliated Sixth People's Hospital.

\section{Micro-CT scanning}

Bone morphologic changes were detected by micro-CT scanning as previously described [21]. In brief, the femoral head was scanned with a micro-CT scanner (Brooke, Germany), and 2-D images were analyzed by CTAn software. Data of the trabecular bone parameters, such as bone mineral density (BMD), bone volume per tissue volume (BV/TV), trabecular thickness (Tb.Th), and trabecular number (Tb.N) were collected.

\section{Angiography}

Angiography was performed as previously described [21]. Briefly, cardia was perfused, and Microfil (Flow Tech, Inc., Inc., Carver, MA, USA) was injected, after which, the rats were placed on the bed for one hour to ensure contrast agent polymerization. Femoral heads were fixed and decalcified. Finally, the samples were scanned, and the femoral head vessels were reconstructed.

\section{Histology and Immunohistochemistry (IHC)}

After the mice were sacrificed, their femoral heads were harvested, decalcificated, and sectioned at a thickness of $4 \mu \mathrm{m}$ in the coronal plane. A part of the sections were subjected to hematoxylin and eosin (H\&E) staining to evaluate the trabecular structure. The expression levels of OCN, Runx2, and CD31 were detected by immunohistochemistry. Tissue paraffin sections were dewaxed and heat-treated with citrate buffer ( $\mathrm{pH}$ 6.0) for $10 \mathrm{~min}$. Endogenous peroxidase activity was inhibited using $0.1 \%$ hydrogen peroxide, and the non-specific-binding sites were blocked with serum goat for $1 \mathrm{~h}$. Then, incubation with primary antibodies against OCN (Abcam, 1:100), Runx2 (Abcam, 1:100), and CD31 (Abcam, 1:100) was conducted overnight at $4{ }^{\circ} \mathrm{C}$. The bound antibodies were detected by the biotin-linked secondary antibodies and $\mathrm{DAB}$ chromogen-conjuncted streptavidin-conjugated HRP enzymes (Beyotime). Finally, the color was developed by 3-3'-diaminobenzidine, counterstaining was performed with hematoxylin, and the slides were observed under a laser confocal scanning microscope (Olympus).

\section{Statistical analysis}

Data were presented as mean \pm standard deviation (SD). Comparisons between groups were performed using one-way ANOVA. All data were analyzed with SPSS 19.0 (SPSS, Chicago, IL, USA), a two tailed $P$-value less than 0.05 was considered statistical significant.

\section{Results}

SDF-1 $\alpha$ overexpression in BMSCs promoted angiogenesis and endothelial cell recruitment in vitro

The characteristics of isolated cells were determined by flow cytometry (Fig. 1a). The cells were positive for CD 44, CD 90, and CD29, but negative for CD 34 and HLA-DR, which are typical biomarkers for BMSCs. Next, the multi-lineage differentiation potential of BMSCs was detected, as shown in Fig. 1b, BMSCs could be differentiated to chondrocytes, osteoblasts and adipocytes, which indicated the stemness of BMSCs. Then, BMSCs were infected with lentiviral vectors carrying the SDF- $1 \alpha$ gene and GFP or only GFP, and stable transgenic GFPBMSCs and SDF-1 $\alpha$-GFP-BMSCs cells were sorted and confirmed by immunofluorescence (Fig. 1c). The expression of SDF-1 $\alpha$ was measured at both the mRNA and protein level, the results of which suggested that cells were successfully transfected with the SDF-1 $\alpha$ gene (Fig. 1d-e). Further, the proliferation and apoptosis trend after SDF-1 $\alpha$ transfection were 

Cellular Physiology Cell Physiol Biochem 2018;46:2561-2575 \begin{tabular}{l|l} 
and Biochemistry Published online: May 14, 2018 & $\begin{array}{l}\text { ( ) 2018 The Author(s). Published by S. Karger AG, Basel } \\
\text { www.karger.com/cpb }\end{array}$
\end{tabular}
Yang et al.: SDF-1 $\alpha$ Promotes Bone Formation in ONFH

investigated. As depicted in Fig. 1f, SDF-1 $\alpha$ transfection in BMSCs had no significant impact on cell proliferation compared with non-transfected BMSCs and GFP-BMSCs. Moreover, SDF$1 \alpha$ transgenic BMSCs exhibited comparable cell apoptosis ratio in contrast to non-transfected BMSCs and GFP-BMSCs, with a death ratio at about 10\% (Fig. 1g-h).

Previous studies reported that SDF-1 was closely associated with angiogenesis and endothelial cell recruitment [35]. Therefore, EA. Hy926 cells were used to evaluate the tube formation activity of transgenic BMSCs. As expected, SDF- $1 \alpha$-GFP-BMSCs had a significantly higher tube formation ability than GFP-BMSCs, which was exerted in a dose-dependent manner (Fig. 2a-d). Then, MP was used to mimic osteonecrosis in vitro. After the post-MP treatment, the tube formation ability was attenuated; however, SDF-1 $\alpha$ overexpression significantly increased its formation ability compared with MP treatment alone (Fig. 2a-d). Moreover, SDF-1 $\alpha$-GFP-BMSCs significantly promoted EA. Hy926 cell proliferation in a dosedependent manner compared with control both in the absence and presence of MP (Fig. 2e). In line with the results obtained in the tube formation assay, SDF- $1 \alpha$-GFP-BMSCs promoted significantly higher cell migration compared with GFP-BMSCs. Moreover, MP lowered the number of migrated cells, and SDF- $1 \alpha$-GFP-BMSCs reversed the effects induced by MP (Fig. 2f-g). Additionally, the expression of CD31, an indicator for angiogenesis, was measured. EA. Hy926 cells were cultured in the supernatants of BMSCs, $20 \%$ SDF- $1 \alpha$-GFP-BMSCs and $100 \%$ SDF- $1 \alpha$-GFP-BMSCs with or without MP for 5 days. Results suggested that CD31 was significantly augmented in dose-dependent way both in the absence and presence of MP (Fig. $2 \mathrm{~h}$ ). These results suggest that SDF-1 $\alpha$ overexpression promotes angiogenesis in vitro.

Fig. 1. Characteristics of isolated human bone marrow-derived stromal stem cells (BMSCs) and transfection efficacy evaluation. (a) The isolated BMSCs were positive for CD44, CD90, and CD29, but negative for CD34 and HLA-DR. The $\mathrm{X}$ axis represents fluorescence intensity. (b) BMSCs were differentiated to chondrocytes, osteoblasts and adipocytes. (c) BMSCs were successfully transfected with lentiviral vectors, as indicated by immunofluorescence. The expression of SDF-1 in transgenic BMSCs was measured at (c) mRNA and (d) protein level. (f) The effect of SDF- $1 \alpha$ transgenic BMSCs on cell proliferation. (g) The effect of SDF-1 $\alpha$ transgenic BMSCs on cell apoptosis was measured by flow cytometry, Q1

a

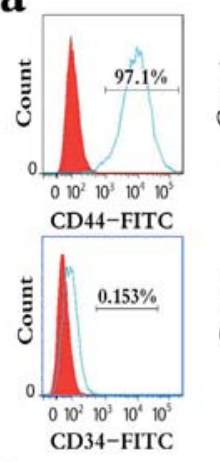

b

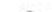

Osteogenic
differentiation

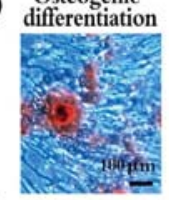

e
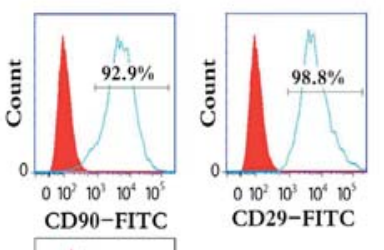

C GFP-BMSCs
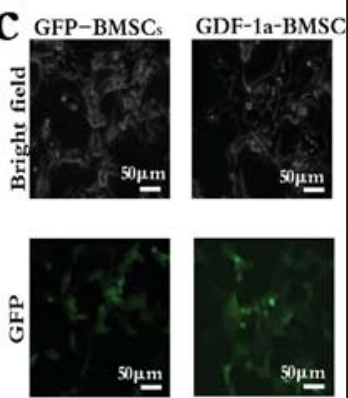

$010^{2} 10^{3} 10^{4} 10^{5}$

HLA-DR-FITC
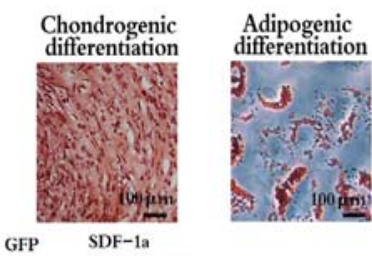

$\begin{array}{ll}\text { GFP } & \text { SDF-1a } \\ - \text { BMSCs } & - \text { GFP-BMSCS }\end{array}$
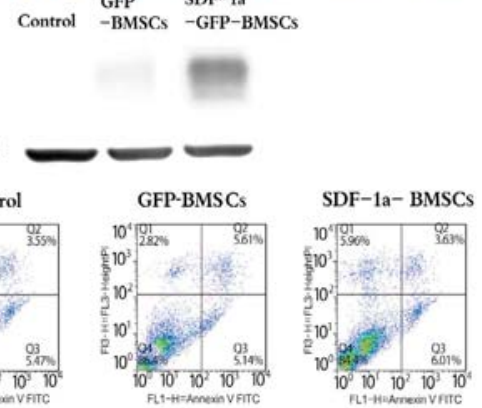

represents necrotic cells, Q2 means late apoptotic cells, Q3 stands for early apoptotic cells and Q4 stands for live cells. (h) Statistical analysis for apoptotic cells. Each experiment was performed at least three times. ${ }^{*} \mathrm{P}<0.05$. 


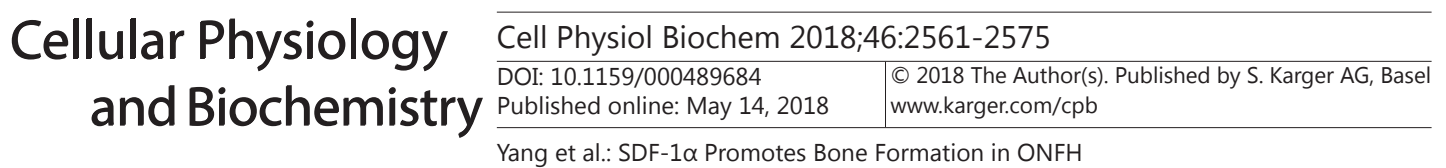

Osteogenic-related proteins were upregulated post SDF-1 $\alpha$ overexpression in BMSCS

Osteogenic proteins, OCN, Runx2 and ALP are essential for osteogenesis and their upregulation is a positive indicator for osteogenesis $[19,21]$. Hence, the expression of these proteins was measured in our examination. Expectedly, the expression of ALP, Runx2, and OCN in the SDF-1 $\alpha$ overexpression group at the mRNA level was significantly upregulated compared with that in the control group (Fig. 3a-c). Their expression was attenuated by MP, and SDF-1 $\alpha$ overexpression in BMSCs reversed the effects induced by MP (Fig. 3a-c). The expression of OCN and Runx 2 at the protein level was in line with their mRNA level (Fig. 3d). p-Smad1/5, another indicator of osteogenic protein [40], was also upregulated (Fig. 3d). Furthermore, the expression of ALP was decreased by MP, and this inhibition was significantly reversed by SDF- $1 \alpha$-GFP-BMSCs in a dose-dependent manner (Fig. 3e). Alizarin red staining revealed that more calcium nodules were available in SDF- $1 \alpha$-GFP-BMSCs than in the GFP-BMSCs and control groups. In contrast, fewer calcium nodules were observed postMP treatment; therefore, SDF- $1 \alpha$-GFP-BMSCs significantly increased the quantity of nodules in a dose-dependent manner (Fig. 3f). These results indicate that SDF-1 $\alpha$ overexpression in BMSCs promoted osteogenesis in vitro.

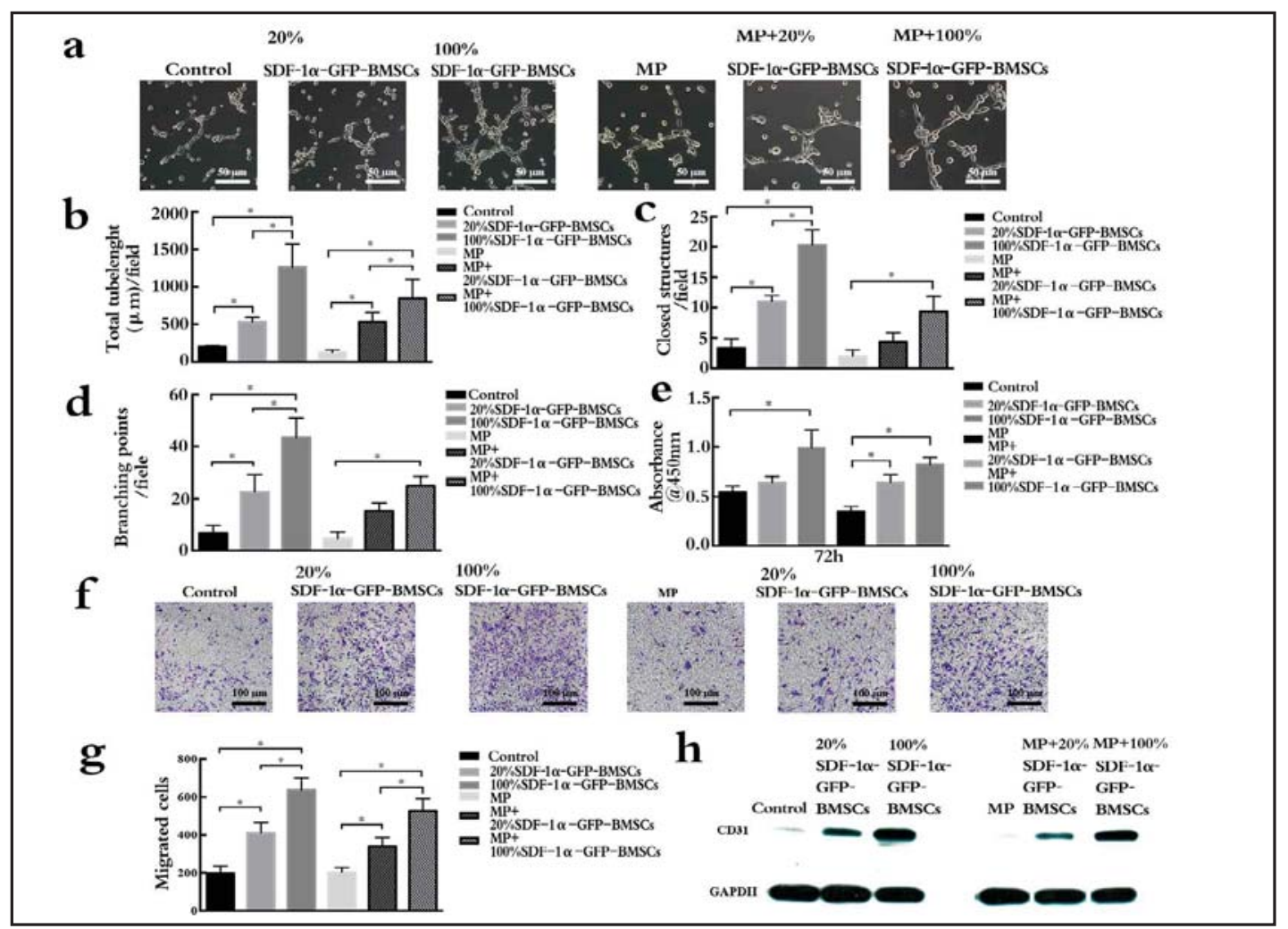

Fig. 2. SDF-1 $\alpha$ overexpression in BMSCs promoted angiogenesis in vitro. (a) Cell supernatants of SDF$1 \alpha$-GFP-BMSCs promoted significantly higher tube formation in a dose-dependent manner as compared with GFP-BMSCs (control group). Tube formation was attenuated by methylprednisolone (MP), whereas SDF-1 $\alpha$-GFP-BMSCs reversed the effects caused by MP in a dose-dependent manner. The changes of (b) total tube length, (c) closed structures, and (d) branching points were in line with the results observed for tube formation. (e) The SDF-1 $\alpha$-GFP-BMSCs promoted EA. Hy926 cell proliferation in a dose-dependent manner in the absence or presence of MP. (f) Cell supernatants of SDF-1-GFP-BMSCs promoted significantly more pronouncedly endothelial cell recruitment in a dose-dependent manner as compared with GFPBMSCs (control group). Endothelial cell recruitment efficacy was attenuated by methylprednisolone (MP), whereas SDF-1 $\alpha$-GFP-BMSCs reversed the effects caused by MP in a dose-dependent manner. (g) Cell count of migrated cells. (h) The expression of CD 31 in EA. Hy926 cells was measured by western blot. Each experiment was performed at least three times. ${ }^{*} \mathrm{P}<0.05$.

\section{KARGER}



Cellular Physiology Cell Physiol Biochem 2018;46:2561-2575 \begin{tabular}{c|c|c|} 
DOI: 10.1159/000489684 & O 2018 The Author(s). Published by S. Karger AG, Basel \\
www.karger.com/cpb
\end{tabular}

Yang et al.: SDF- $1 \alpha$ Promotes Bone Formation in ONFH
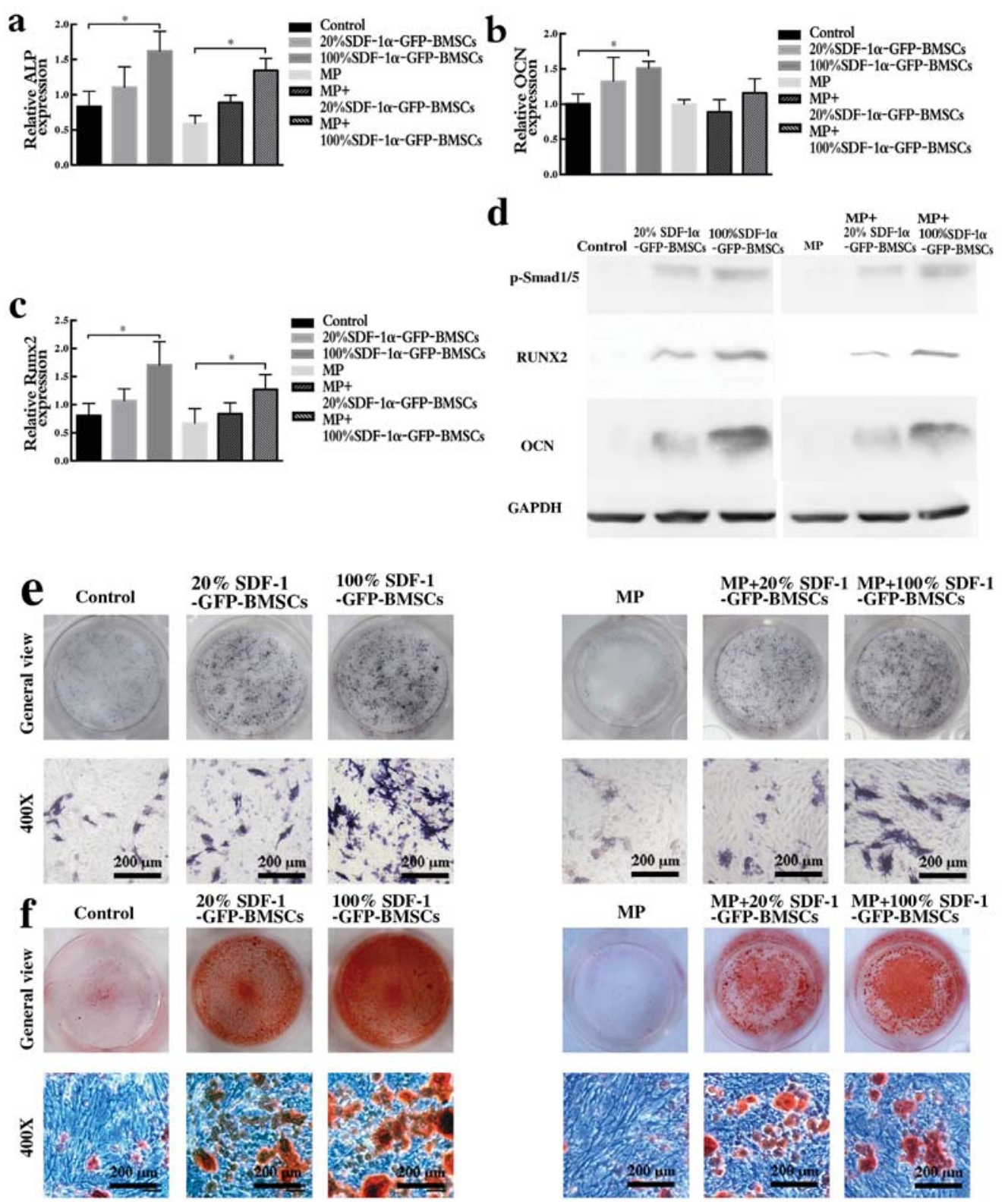

Fig. 3. Osteogenic-related proteins were upregulated by SDF-1 overexpression in BMSCs in vitro. The expression levels of osteogenic-related proteins (a) ALP, (b) OCN, and (c) Runx2 were upregulated at the mRNA level in SDF-1 $\alpha$-GFP-BMSCs. MP decreased the expression of ALP, OCN, and Runx2, and their expression was restored by SDF-1 overexpression. (d) The expression levels of p-Smad1/5, OCN, and Runx2 were increased in SDF-1 $\alpha$-GFP-BMSCs in a dose-dependent manner, whereas their expression in SDF-1 $\alpha$-GFPBMSCs was not affected by MP. (e) The expression of ALP was determined by ALP staining. ALP expression was increased by SDF-1 $\alpha$-GFP-BMSCs in a dose-dependent manner, and the MP-decreased ALP expression was reversed by SDF- $1 \alpha$ overexpression in BMSCs. (f) SDF- $1 \alpha$-GFP-BMSCs induced the formation of a higher number of calcium nodules than that in the control group in a dose-dependent manner which was evidenced by Alizarin red staining. Fewer calcium nodules were observed in the MP group than in the control group; the mineralization of BMSCs was significantly improved in SDF-1 $\alpha$ overexpression BMSCs. Each experiment was performed at least three times. ${ }^{*} \mathrm{P}<0.05$. 


\section{Cellular Physiology Cell Physiol Biochem 2018;46:2561-2575 \begin{tabular}{l|l} 
and Biochemistry Published online: May 14, 2018 & $\begin{array}{l}\text { () 2018 The Author(s). Published by S. Karger AG, Basel } \\
\text { www.karger.com/cpb }\end{array}$ \\
\hline
\end{tabular} \\ Yang et al.: SDF-1 $\alpha$ Promotes Bone Formation in ONFH}

SDF-1 $\alpha$ overexpression in BMSCs accelerates osteogenesis in an ONFH rat model

Next, the role of SDF- $1 \alpha$ in ONFH was established in an MP-induced ONFH rat model. The ONFH model was successfully generated as indicated by femoral head osteonecrosis (Fig. 4a). BMSCs transplantation partially promoted osteogenesis, whereas SDF-1 $\alpha$ overexpression in BMSCs significantly enhanced the osteogenesis in ONFH (Fig. 4a). The expression levels of OCN and Runx2 were decreased by MP, and their expression at protein and mRNA level was restored by SDF- $1 \alpha$-GFP-BMSCs transplantation in the femoral head tissues (Fig. 4b-d). The presence of the transplanted BMSCs was confirmed by GFP fluorescence, and the results suggested that transgenic BMSCs were successfully located in the femoral head (Fig. 5a). The trabecular changes in the subchondral area of the femoral heads were visualized by micro-CT scanning. Six weeks post-MP treatment, osteonecrosis of the femoral head was obvious, whereas SDF- $1 \alpha$-GFP-BMSCs significantly attenuated the MPinduced osteonecrosis (Fig. 5b). MP significantly lowered BMD values in the experimental rats, whereas the transplantation of SDF- $1 \alpha$-GFP-BMSCs significantly increased them (Fig. $5 c)$. In addition, other bone parameters, such as BV/TV, Tb.Th, and Tb.N, were improved in SDF-1 $\alpha$-GFP-BMSCs-injected rats as compared with rats injected with MP + GFP-BMSCs or MP alone (Fig. $5 \mathrm{~d}$ ). These results indicate that SDF-1 $\alpha$ overexpression accelerates the osteogenesis of ONFH in vivo.

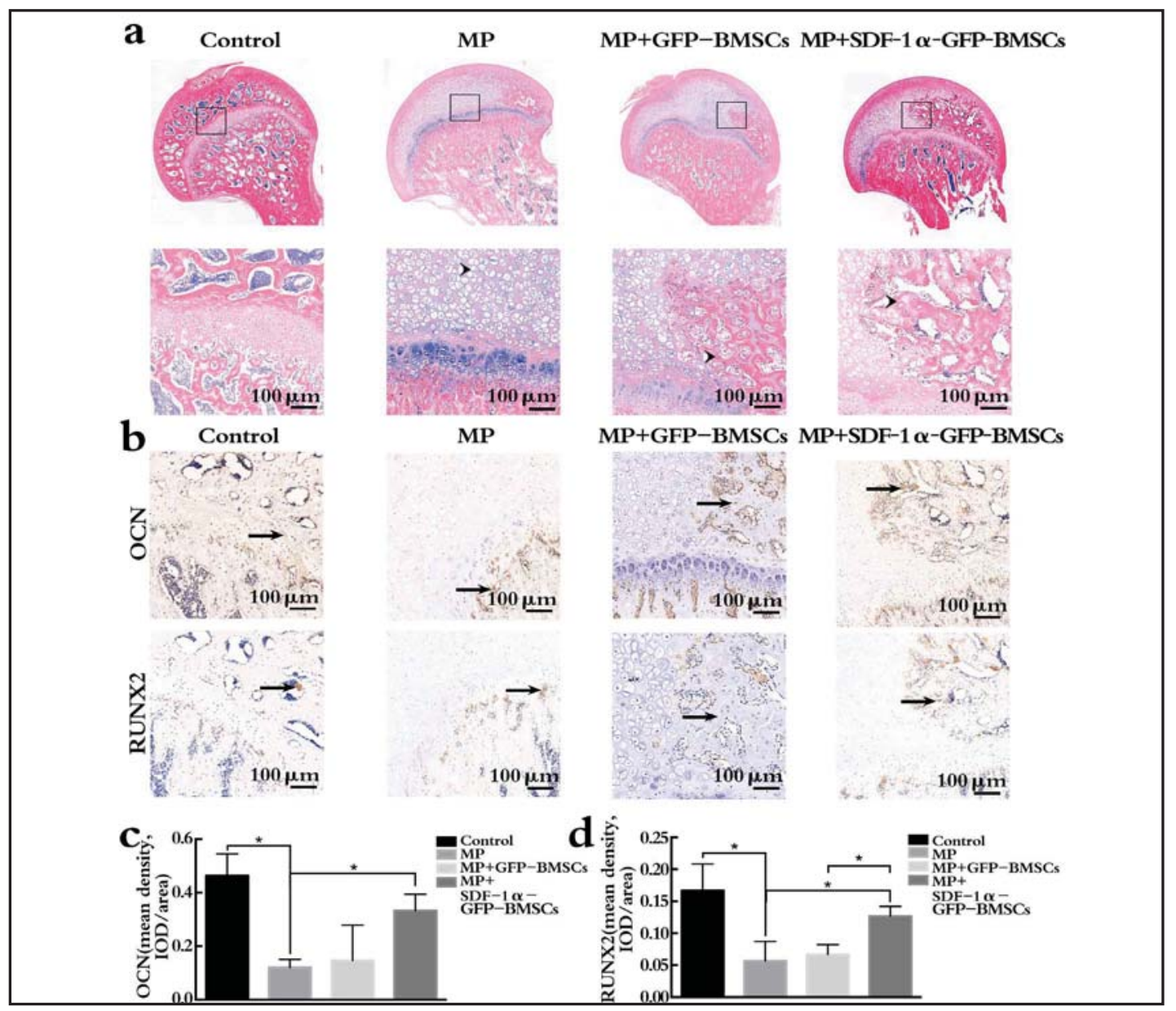

Fig. 4. SDF-1 $\alpha$-GFP-BMSCs promote osteogenesis in vivo. (a) The overexpression of SDF-1 $\alpha$ in BMSCs attenuated the morphological changes induced by MP as indicated by H\&E staining. Triangle indicates bone necrosis. (b) SDF-1 $\alpha$-GFP-BMSCs promoted the expression of Runx2 and OCN in spite of the presence of MP. Arrows indicate the expression of OCN (upper lane) or RUNX2 (lower lane). (c) Density evaluation of OCN. (d) Density evaluation of Runx2. Each experiment was performed at least three times. ${ }^{*} \mathrm{P}<0.05$. 


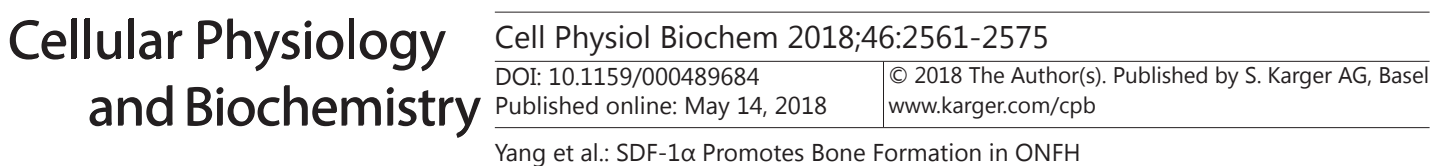

\section{Angiogenesis was promoted by SDF-1 $\alpha$ overexpression}

Previous results suggested that SDF- $1 \alpha$ overexpression in BMSCs promoted in vitro angiogenesis, which is essential for osteogenesis. However, its function in vivo remains unexplored. We utilized angiography to directly visualize angiogenesis in vivo. As shown in Fig. 6a, MP not only deteriorated the structure of the femoral head, but also destroyed its vessels. In contrast, SDF-1 $\alpha$-GFP-BMSCs transplantation resulted in obvious signs of angiogenesis and significantly increased the vessel volume compared with that in the control group (Fig. 6a, d). The expression of CD31, an indicator for angiogenesis [41], was also examined. CD31 expression was significantly decreased by MP; nevertheless, the inhibition effect was reversed post-SDF-1 $\alpha$-GFP-BMSCs transplantation (Fig. 6b-c). Therefore, SDF-1 $\alpha$ overexpression in BMSCs promotes angiogenesis in rats with ONFH.

\section{Discussion}

Previous studies suggested that multiple factors play roles in BMSC-induced osteogenesis $[17,19,21]$; however, the underlying mechanism is not fully understood. By introducing the lentiviral vectors expressing SDF- $1 \alpha$ into BMSCs, the present study illustrated that SDF- $1 \alpha$ promoted the efficacy of BMSC-induced bone formation by angiogenesis and osteogenesis. For the first time, these results provide evidence that SDF- $1 \alpha$ may be a potential therapeutic target against $\mathrm{ONFH}$.

Stem cell transplantation has been widely used for the treatment of diseases, such as leukemia [42], diabetic neuropathy [43], and erectile dysfunction [44]. However, satisfactory efficacy is not always achieved by the application of transplantation of stem cells alone. In previous investigations, it has been found that the combination of stem cell transplantation with other therapeutic methods could affect the efficiency of stem cell transplantation [4548]. On the other hand, BMSCs transplantation has been revealed as a promising strategy

Fig. 5. SDF- $1 \alpha$-GFP-BMSCs promote osteogenesis as indicated by trabecular bone parameters. (a) Immunohistochemistry staining for GFP indicated that the transgenic BMSCs were located in the femoral head. Arrows indicate the localization of GFP labeled BMSCs. (b) Direct visualization of the morphological changes: SDF$1 \alpha$-GFP-BMSCs reversed MP-induced osteonecrosis. Changes of the trabecular bone parameters: (c) bone mineral density (BMD); (d) bone volume per tissue volume (BV/TV); (e) trabecular thickness (Tb.Th); and (f) trabecular number (Tb.N). Each experiment was performed at least three times. $* \mathrm{P}<0.05$.

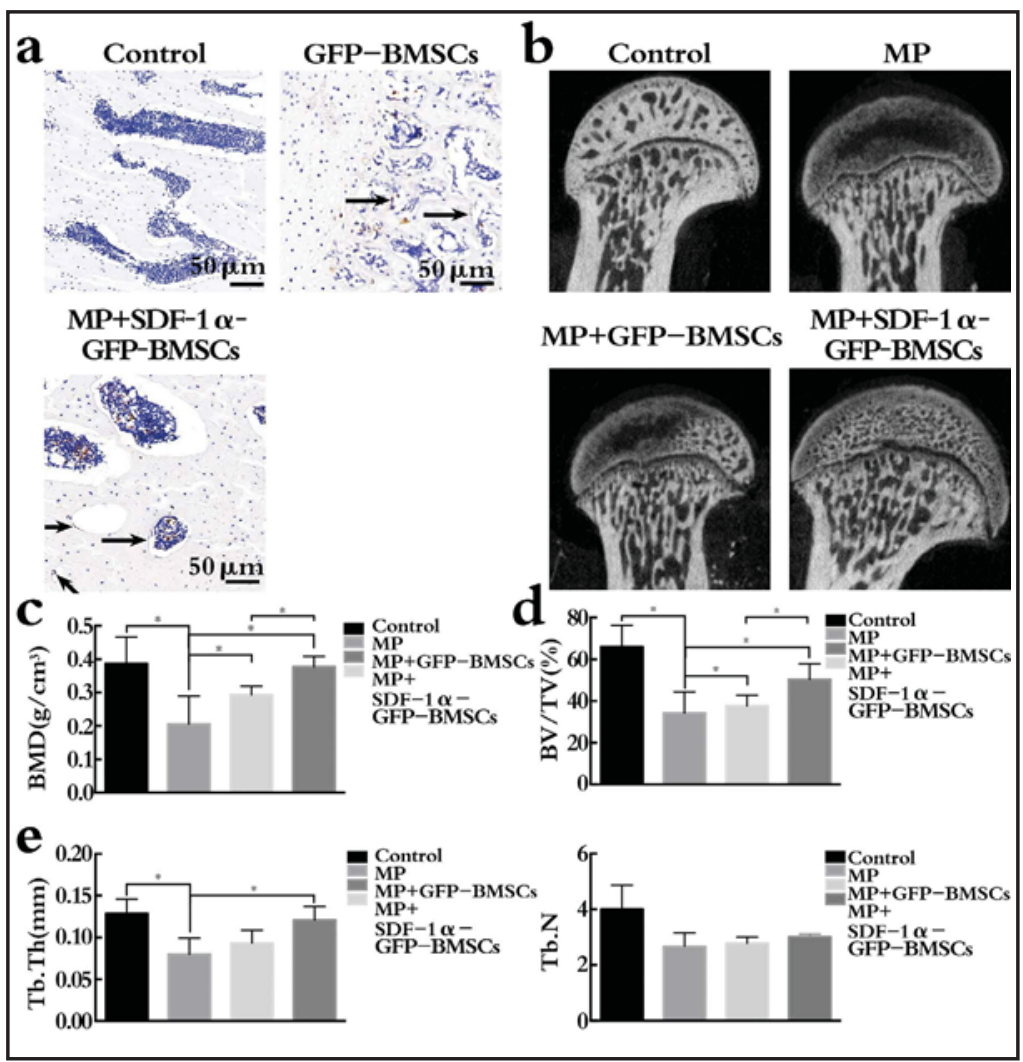




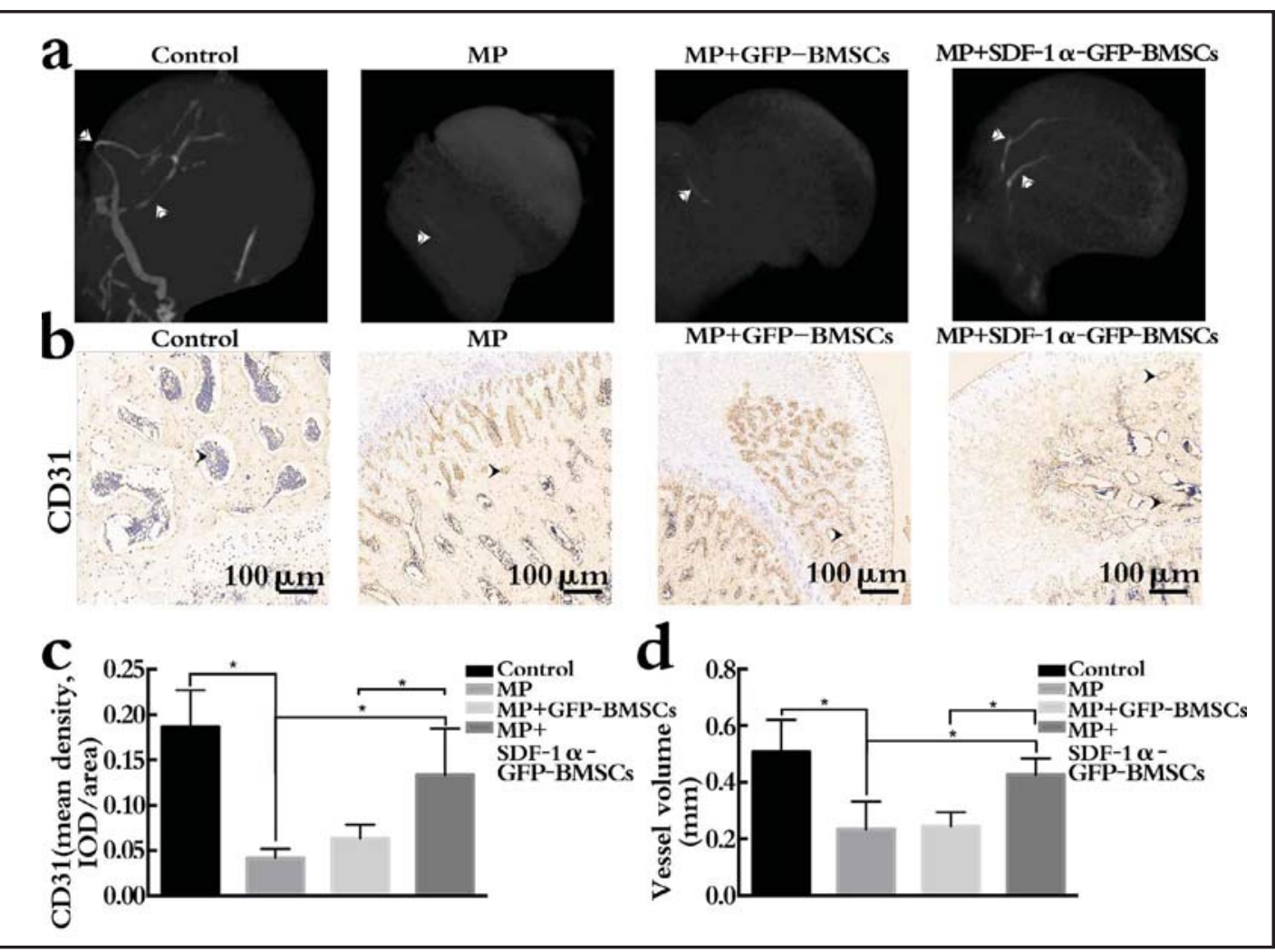

Fig. 6. SDF-1 $\alpha$-GFP-BMSCs promote angiogenesis in vivo. (a) SDF-1 $\alpha$ overexpression in BMSCs promotes vascularization as indicated by angiography. Triangles indicate vessels in bones. (b) The expression of angiogenesis indicator, CD31, was upregulated by SDF-1 $\alpha$-GFP-BMSCs despite the presence of MP. Triangles indicate the expression of CD 31. (c) Density evaluation of CD31. (d) Vessel volume calculation. Each experiment was performed at least three times. ${ }^{*} \mathrm{P}<0.05$.

for ONFH treatment; however, only patients with medium-size lesions could benefit from its application $[15,16]$. The findings of other studies suggested that the treatment with SC79 (an Akt activator) and Vitamin K2 significantly improved the efficacy of osteogenesis in animals $[17,21]$. Furthermore, transgenic overexpression of P-glycoprotein or VEGF165 in BMSCs significantly increased stem cell-induced osteogenesis as well $[19,20]$. In addition, SDF-1 was found to be closely associated with osteogenesis and angiogenesis $[49,50]$. In the present study, we showed that SDF-1 $\alpha$ overexpression in BMSCs significantly promoted bone regeneration by osteogenesis and angiogenesis. To the best of our knowledge, this is the first report evidencing that SDF-1 promotes BMSCs differentiation towards osteogenesis and angiogenesis in ONFH treatment.

Runx2 is essential in BMSC differentiation [51]. In the present study, we discovered that the expression of Runx2 was decreased post-MP treatment, whereas it was upregulated after the transplantation of SDF- $1 \alpha$-GFP-BMSCs, which is consistent with the results of previous studies [52, 53]. Lingqian et al. reported that the cotherapy with the parathyroid hormone (PTH) and SDF-1 promoted osteogenic differentiation of human periodontal ligament stem cells by enhancing OCN expression and ALP activity [54], which is in line with the findings of the present study. Osteoblast differentiation is key to bone formation, in which bone morphogenetic protein-2/Smad signaling pathway is involved [55]. As shown in Fig. 3d, in our study, SDF- $1 \alpha$ overexpression activated Smad1/5 phosphorylation, suggesting that SDF$1 \alpha$ activates osteoblast differentiation in vitro. Micro-CT scanning directly and H\&E staining indirectly showed that SDF-1 $\alpha$ overexpression in BMSCs significantly reversed BP-induced osteonecrosis. Furthermore, trabecular bone parameters, such as BMD, BV/TV, Tb.Th, and 


\section{Cellular Physiology Cell Physiol Biochem 2018;46:2561-2575 \begin{tabular}{ll|l} 
and Biochemistry & $\begin{array}{l}\text { DOI: 10.1159/000489684 } \\
\text { Published online: May 14, } 2018\end{array}$ & $\begin{array}{l}\text { ( ) } 2018 \text { The Author(s). Published by S. Karger AG, Basel } \\
\text { www.karger.com/cpb }\end{array}$ \\
\hline
\end{tabular}}

Yang et al.: SDF-1 $\alpha$ Promotes Bone Formation in ONFH

Tb.N were increased in SDF-1 $\alpha$-GFP-BMSCs. Therefore, we could reasonably conclude that multiple factors were involved in SDF- $1 \alpha$-stimulated bone regeneration in ONFH.

In addition to osteogenesis, BMSCs enhance vascularization and blood vessel regeneration, processes which are critical to the survival of newly formed bone tissues and bone regeneration [56]. Recent studies have shown that SDF-1 not only participates in cell migration, but also promotes angiogenesis in damaged and wounded tissues [57-59]. The present study revealed that SDF- $1 \alpha$ overexpression in BMSCs promoted tube formation and endothelial cell recruitment in vitro. In addition, we further confirmed that SDF-1 $\alpha$-GFPBMSCs increased the vascularization and angiogenesis, as directly evidenced by angiography, as well as the vessel volume. Furthermore, the expression of CD31, a well-known biomarker for angiogenesis, was enhanced. These results suggest that SDF- $1 \alpha$ overexpression in BMSCs can potentiate BMSCs angiogenesis both in vitro and in vivo, indicating that angiogenesis is involved in SDF-1 promotion of bone regeneration.

In conclusion, our results indicate that SDF- $1 \alpha$ overexpression had beneficial effects in BMSCs transplantation for the treatment of ONFH by promoting angiogenesis and osteogenesis. Our findings suggest that targeting SDF- $1 \alpha$ is a potential therapeutic strategy for ONFH treatment. However, further studies are warranted to reveal the function of SDF-1 in larger animal models of ONFH.

\section{Acknowledgements}

This study was funded by the National Natural Science Foundation of China (No. 81572121).

\section{Disclosure statement}

All authors declare that they have no conflict of interests.

\section{References}

1 Lazaro LE, Dyke JP, Thacher RR, Nguyen JT, Helfet DL, Potter HG, Lorich DG: Focal osteonecrosis in the femoral head following stable anatomic fixation of displaced femoral neck fractures. Arch Orthop Trauma Surg 2017; 137:1529-1538.

2 Zalavras CG, Lieberman JR: Osteonecrosis of the femoral head: evaluation and treatment. J Am Acad Orthop Surg 2014;22:455-464.

-3 Silva LL, Castelar M, Matos MA: Quality of Life in Pediatric Patients with Avascular Necrosis of the Femoral Head. Ortop Traumatol Rehabil 2016;18:445-449.

4 Kim SC, Lim YW, Jo WL, Park DC, Lee JW, Kang WW, Kim YS: Surgical accuracy, function, and quality of life of simultaneous versus staged bilateral Total hip Arthroplasty in patients with Osteonecrosis of the femoral head. BMC Musculoskelet Disord 2017;18:266.

-5 Tan G, Kang PD, Pei FX: Glucocorticoids affect the metabolism of bone marrow stromal cells and lead to osteonecrosis of the femoral head: a review. Chin Med J (Engl) 2012;125:134-139.

6 Liu F, Wang W, Yang L, Wang B, Wang J, Chai W, Zhao D: An epidemiological study of etiology and clinical characteristics in patients with nontraumatic osteonecrosis of the femoral head. J Res Med Sci 2017;22:15.

7 Yu Y, Xie Z, Wang J, Chen C, Du S, Chen P, Li B, Jin T, Zhao H: Single-nucleotide polymorphisms of MMP2 in MMP/TIMP pathways associated with the risk of alcohol-induced osteonecrosis of the femoral head in Chinese males: A case-control study. Medicine (Baltimore) 2016;95:e5407.

8 Capone A, Bienati F, Torchia S, Podda D, Marongiu G: Short stem total hip arthroplasty for osteonecrosis of the femoral head in patients 60 years or younger: a 3- to 10-year follow-up study. BMC Musculoskelet Disord 2017;18:301. 


\section{Cellular Physiology Cell Physiol Biochem 2018;46:2561-2575 \begin{tabular}{c|l|l} 
DOI: 10.1159/000489684 & ( ) 2018 The Author(s). Published by S. Karger AG, Basel
\end{tabular}

Yang et al.: SDF-1 $\alpha$ Promotes Bone Formation in ONFH

9 Yuan W, Cui L, Li G, Wang N, Zhang P, Zhang Y, Yu N, Wang H, Zhu J, Yang L, Huang J: Recombinant neuritin affects the senescence, apoptosis, proliferation, and migration of rat bone marrow-derived mesenchymal stem cells. Biotechnol Lett 2017; 39(11):1649-1655.

10 Shiraishi K, Kamei N, Takeuchi S, Yanada S, Mera H, Wakitani S, Adachi N, Ochi M: Quality Evaluation of Human Bone Marrow Mesenchymal Stem Cells for Cartilage Repair. Stem Cells Int 2017;2017:8740294.

11 Hostettler KE, Gazdhar A, Khan P, Savic S, Tamo L, Lardinois D, Roth M, Tamm M, Geiser T: Multipotent mesenchymal stem cells in lung fibrosis. PLoS One 2017;12:e0181946.

12 Dhoke NR, Geesala R, Das A: Low oxidative stress-mediated proliferation via JNK-FOXO3a-Catalase signaling in transplanted adult stem cells promotes wound tissue regeneration. Antioxid Redox Signal DOI: 10.1089/ars.2016.6974.

-13 Fahy N, Alini M, Stoddart MJ: Mechanical stimulation of mesenchymal stem cells: Implications for cartilage tissue engineering. J Orthop Res 2017; 36(1):52-63.

14 Sha Y, Lv Y, Xu Z, Yang L, Hao X, Afandi R: MGF E peptide pretreatment improves the proliferation and osteogenic differentiation of BMSCs via MEK-ERK1/2 and PI3K-Akt pathway under severe hypoxia. Life Sci 2017; 15;189:52-62.

15 Rubessa M, Polkoff K, Bionaz M, Monaco E, Milner DJ, Holllister SJ, Goldwasser MS, Wheeler MB: Use of Pig as a Model for Mesenchymal Stem Cell Therapies for Bone Regeneration. Anim Biotechnol 2017:1-13.

16 Kang JS, Moon KH, Kim BS, Kwon DG, Shin SH, Shin BK, Ryu DJ: Clinical results of auto-iliac cancellous bone grafts combined with implantation of autologous bone marrow cells for osteonecrosis of the femoral head: a minimum 5-year follow-up. Yonsei Med J 2013;54:510-515.

17 Chen YX, Tao SC, Xu ZL, Yin WJ, Zhang YL, Yin JH, Gao YS, Zhang CQ: Novel Akt activator SC-79 is a potential treatment for alcohol-induced osteonecrosis of the femoral head. Oncotarget 2017;8:31065-31078.

18 Chen YX, Zhu DY, Xu ZL, Yin JH, Yu XW, Mei J, Gao YS, Zhang CQ: The Protective Effect of Cordycepin On Alcohol-Induced Osteonecrosis of the Femoral Head. Cell Physiol Biochem 2017;42:2391-2403.

19 Han N, Li Z, Cai Z, Yan Z, Hua Y, Xu C: P-glycoprotein overexpression in bone marrow-derived multipotent stromal cells decreases the risk of steroid-induced osteonecrosis in the femoral head. J Cell Mol Med 2016;20:2173-2182.

20 Hang D, Wang Q, Guo C, Chen Z, Yan Z: Treatment of osteonecrosis of the femoral head with VEGF165 transgenic bone marrow mesenchymal stem cells in mongrel dogs. Cells Tissues Organs 2012;195:495506.

-21 Zhang YL, Yin JH, Ding H, Zhang W, Zhang CQ Gao YS: Vitamin K2 Prevents Glucocorticoid-induced Osteonecrosis of the Femoral Head in Rats. International journal of biological sciences 2016;12:347-358.

22 Peng WX, Wang L: Adenovirus-Mediated Expression of BMP-2 and BFGF in Bone Marrow Mesenchymal Stem Cells Combined with Demineralized Bone Matrix For Repair of Femoral Head Osteonecrosis in Beagle Dogs. Cell Physiol Biochem 2017;43:1648-1662.

23 Zhou W, Guo S, Liu M, Burow ME, Wang G: Targeting CXCL12/CXCR4 Axis in Tumor Immunotherapy. Curr Med Chem DOI: 10.2174/0929867324666170830111531.

24 Jeng KS, Jeng CJ, Jeng WJ, Chang CF, Sheen IS: Role of C-X-C chemokine ligand 12/C-X-C chemokine receptor 4 in the progression of hepatocellular carcinoma. Oncol Lett 2017;14:1905-1910.

25 Liu H, Liu H, Deng X, Chen M, Han X, Yan W, Wang N: CXCR4 antagonist delivery on decellularized skin scaffold facilitates impaired wound healing in diabetic mice by increasing expression of SDF-1 and enhancing migration of CXCR4-positive cells. Wound Repair Regen 2017; 25(4):652-664.

-26 Tang Q, Luo C, Lu B, Fu Q Yin H, Qin Z, Lyu D, Zhang L, Fang Z, Zhu Y, Yao K: Thermosensitive chitosan-based hydrogels releasing stromal cell derived factor-1 alpha recruit MSC for corneal epithelium regeneration. Acta Biomater 2017;61:101-113.

27 Shafiq M, Kong D, Kim SH: SDF-1alpha peptide tethered polyester facilitates tissue repair by endogenous cell mobilization and recruitment. J Biomed Mater Res A 2017;105:2670-2684.

28 Tang CH, Chuang JY, Fong YC, Maa MC, Way TD, Hung CH: Bone-derived SDF-1 stimulates IL-6 release via CXCR4, ERK and NF-kappaB pathways and promotes osteoclastogenesis in human oral cancer cells. Carcinogenesis 2008;29:1483-1492.

29 Kortesidis A, Zannettino A, Isenmann S, Shi S, Lapidot T, Gronthos S: Stromal-derived factor-1 promotes the growth, survival, and development of human bone marrow stromal stem cells. Blood 2005;105:3793-3801. 


\section{Cellular Physiology Cell Physiol Biochem 2018;46:2561-2575

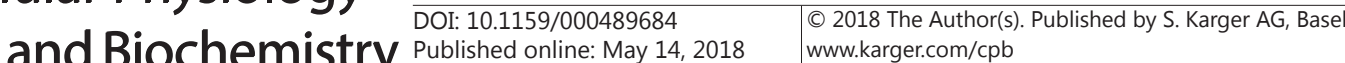

Yang et al: SDF-1 $\alpha$ Promotes Bone Formation in ONFH

30 Hosogane N, Huang Z, Rawlins BA, Liu X, Boachie-Adjei O, Boskey AL, Zhu W: Stromal derived factor-1 regulates bone morphogenetic protein 2-induced osteogenic differentiation of primary mesenchymal stem cells. Int J Biochem Cell Biol 2010;42:1132-1141.

-31 Zhu W, Liang G, Huang Z, Doty SB, Boskey AL: Conditional inactivation of the CXCR4 receptor in osteoprecursors reduces postnatal bone formation due to impaired osteoblast development. J Biol Chem 2011;286:26794-26805.

-32 Toupadakis CA, Wong A, Genetos DC, Chung DJ, Murugesh D, Anderson MJ, Loots GG, Christiansen BA, Kapatkin AS, Yellowley CE: Long-term administration of AMD3100, an antagonist of SDF-1/CXCR4 signaling, alters fracture repair. J Orthop Res 2012;30:1853-1859.

-33 Liu C, Weng Y, Yuan T, Zhang H, Bai H, Li B, Yang D, Zhang R, He F, Yan S, Zhan X, Shi Q: CXCL12/CXCR4 signal axis plays an important role in mediating bone morphogenetic protein 9-induced osteogenic differentiation of mesenchymal stem cells. Int J Med Sci 2013;10:1181-1192.

- 34 Jones GN, Moschidou D, Lay K, Abdulrazzak H, Vanleene M, Shefelbine SJ, Polak J, de Coppi P, Fisk NM, Guillot PV: Upregulating CXCR4 in human fetal mesenchymal stem cells enhances engraftment and bone mechanics in a mouse model of osteogenesis imperfecta. Stem Cells Transl Med 2012;1:70-78.

35 Walenkamp AME, Lapa C, Herrmann K, Wester HJ: CXCR4 Ligands: The Next Big Hit? J Nucl Med 2017;58:77S-82S.

-36 Wang F, Schmidt H, Pavleska D, Wermann T, Seekamp A, Fuchs S: Crude Fucoidan Extracts Impair Angiogenesis in Models Relevant for Bone Regeneration and Osteosarcoma via Reduction of VEGF and SDF1. Mar Drugs 2017;15:pii:E186.

37 Qin G, Chen Y, Li H, Xu S, Li Y, Sun J, Rao W, Chen C, Du M, He K, Ye Y: Melittin inhibits tumor angiogenesis modulated by endothelial progenitor cells associated with the SDF-1alpha/CXCR4 signaling pathway in a UMR-106 osteosarcoma xenograft mouse model. Mol Med Rep 2016;14:57-68.

-38 Perrucci GL, Straino S, Corliano M, Scopece A, Napolitano M, Berk BC, Lombardi F, Pompilio G, Capogrossi MC, Nigro P: Cyclophilin A modulates bone marrow-derived CD117(+) cells and enhances ischemiainduced angiogenesis via the SDF-1/CXCR4 axis. Int J Cardiol 2016;212:324-335.

-39 Neve A, Corrado A, Cantatore FP: Osteocalcin: skeletal and extra-skeletal effects. J Cell Physiol 2013;228:1149-1153.

40 Zhou Q Ren X, Bischoff D, Weisgerber DW, Yamaguchi DT, Miller TA, Harley BAC, Lee JC: Nonmineralized and Mineralized Collagen Scaffolds Induce Differential Osteogenic Signaling Pathways in Human Mesenchymal Stem Cells. Adv Healthc Mater 2017;6(23).

41 Bozec A, Zangari J, Butori-Pepino M, Ilie M, Lalvee S, Juhel T, Butori C, Brest P, Hofman P, Vouret-Craviari V: MiR-223-3p inhibits angiogenesis and promotes resistance to cetuximab in head and neck squamous cell carcinoma. Oncotarget 2017;8:57174-57186.

42 Heidrich K, Thiede C, Schafer-Eckart K, Schmitz N, Aulitzky WE, Kramer A, Rosler W, Hanel M, Einsele H, Baldus CD, Trappe RU, Stolzel F, Middeke JM, Rollig C, Taube F, Kramer M, Serve H, Berdel WE, Ehninger G, Bornhauser M, Schetelig J, Study Alliance L: Allogeneic Hematopoietic Cell Transplantation in Intermediate Risk Acute Myeloid Leukemia negative for FLT3-ITD, NPM1- or biallelic CEBPA Mutations. Ann Oncol 2017;1;28:2793-2798.

-43 Datta I, Bhadri N, Shahani P, Majumdar D, Sowmithra S, Razdan R, Bhonde R: Functional recovery upon human dental pulp stem cell transplantation in a diabetic neuropathy rat model. Cytotherapy 2017;19:1208-1224.

44 Yiou R: Stem-cell therapy for erectile dysfunction. Biomed Mater Eng 2017;28:S81-S85.

45 Wang X, Liu C, Xu Y, Chen P, Shen Y, Xu Y, Zhao Y, Chen W, Zhang X, Ouyang Y, Wang Y, Xie C, Zhou M, Liu C: Combination of mesenchymal stem cell injection with icariin for the treatment of diabetes-associated erectile dysfunction. PLoS One 2017;12:e0174145.

-46 Nowicki M, Wierzbowska A, Malachowski R, Robak T, Grzybowska-Izydorczyk O, Pluta A, SzmigielskaKaplon A: VEGF, ANGPT1, ANGPT2, and MMP-9 expression in the autologous hematopoietic stem cell transplantation and its impact on the time to engraftment. Ann Hematol 2017;96:2103-2112

47 Sun YQ Huang XJ: [Strategies for improving the outcomes of allogeneic stem cell transplantation in patients with relapsed acute leukemia]. Zhonghua Xue Ye Xue Za Zhi 2017;38:732-736.

-48 Rodrigues-Moreira S, Moreno SG, Ghinatti G, Lewandowski D, Hoffschir F, Ferri F, Gallouet AS, Gay D, Motohashi H, Yamamoto M, Joiner MC, Gault N, Romeo PH: Low-Dose Irradiation Promotes Persistent Oxidative Stress and Decreases Self-Renewal in Hematopoietic Stem Cells. Cell Rep 2017;20:3199-3211. 


\section{Cellular Physiology Cell Physiol Biochem 2018;46:2561-2575 \begin{tabular}{ll|l}
\cline { 3 - 3 } DOI: 10.1159/000489684 & () 2018 The Author(s). Published by S. Karger AG, Basel
\end{tabular} and Biochemistry Published online: May 14, 2018 www.karger.com/cpb}

Yang et al.: SDF- $1 \alpha$ Promotes Bone Formation in ONFH

49 Kaku M, Akiba Y, Akiyama K, Akita D, Nishimura M: Cell-based bone regeneration for alveolar ridge augmentation--cell source, endogenous cell recruitment and immunomodulatory function. J Prosthodont Res 2015;59:96-112.

50 Zhong J, Rajagopalan S: Dipeptidyl Peptidase-4 Regulation of SDF-1/CXCR4 Axis: Implications for Cardiovascular Disease. Front Immunol 2015;6:477.

-51 Sun M, Chi G, Li P, Lv S, Xu J, Xu Z, Xia Y, Tan Y, Xu J, Li L, Li Y: Effects of Matrix Stiffness on the Morphology, Adhesion, Proliferation and Osteogenic Differentiation of Mesenchymal Stem Cells. Int J Med Sci 2018;15:257-268.

52 Koromila T, Baniwal SK, Song YS, Martin A, Xiong J, Frenkel B: Glucocorticoids antagonize RUNX2 during osteoblast differentiation in cultures of ST2 pluripotent mesenchymal cells. J Cell Biochem 2014;115:2733.

53 Baniwal SK, Shah PK, Shi Y, Haduong JH, Declerck YA, Gabet Y, Frenkel B: Runx2 promotes both osteoblastogenesis and novel osteoclastogenic signals in ST2 mesenchymal progenitor cells. Osteoporos Int 2012;23:1399-1413.

54 Du L, Feng R, Ge S: PTH/SDF-1alpha cotherapy promotes proliferation, migration and osteogenic differentiation of human periodontal ligament stem cells. Cell Prolif 2016;49:599-608.

-55 Yang X, Huo H, Xiu C, Song M, Han Y, Li Y, Zhu Y: Inhibition of osteoblast differentiation by aluminum trichloride exposure is associated with inhibition of BMP-2/Smad pathway component expression. Food Chem Toxicol 2016;97:120-126.

56 Zhang L, Zhou Y, Sun X, Zhou J, Yang P: CXCL12 overexpression promotes the angiogenesis potential of periodontal ligament stem cells. Sci Rep 2017;7:10286.

-57 Shabbir A, Cox A, Rodriguez-Menocal L, Salgado M, Van Badiavas E: Mesenchymal Stem Cell Exosomes Induce Proliferation and Migration of Normal and Chronic Wound Fibroblasts, and Enhance Angiogenesis In vitro. Stem Cells Dev 2015;24:1635-1647.

58 Du L, Yang P, Ge S: Stromal cell-derived factor-1 significantly induces proliferation, migration, and collagen type I expression in a human periodontal ligament stem cell subpopulation. J Periodontol 2012;83:379388.

59 Xu X, Zhu F, Zhang M, Zeng D, Luo D, Liu G, Cui W, Wang S, Guo W, Xing W, Liang H, Li L, Fu X, Jiang J, Huang H: Stromal cell-derived factor-1 enhances wound healing through recruiting bone marrow-derived mesenchymal stem cells to the wound area and promoting neovascularization. Cells Tissues Organs 2013;197:103-113. 